\title{
PLANO DE GERENCIAMENTO DE RESÍDUOS DA CONSTRUÇÃO CIVIL: UMA BREVE ABORDAGEM ${ }^{1}$
}

\author{
Ari Aires de Alencar ${ }^{2}$
}

\author{
Edilene Mayumi Murashita Takenaka ${ }^{3}$
}

\begin{abstract}
RESUMO
Os geradores de resíduos da construção civil são responsáveis pela observância dos padrões previstos nas legislações específicas, referentes à disposição final, fazendo sua gestão interna e externa. $O$ compromisso ambiental e a viabilidade econômica devem garantir a sustentabilidade, a condição e a solução para a destinação final dos resíduos, sendo competência da administração municipal adequar os locais para o recebimento de tais resíduos. O objetivo do presente artigo é fomentar novos debates sobre o tema a partir de uma breve abordagem sobre o Plano de Gerenciamento de Resíduos da Construção Civil, e para tal finalidade, a metodologia utilizada foi o levantamento de dados obtidos por meio de pesquisa bibliográfica.
\end{abstract}

Palavras-chave: Resíduos da construção civil. Gestão de resíduos. Meio ambiente.

\section{PLAN OF CIVIL CONSTRUCTION RESIDUES MANAGEMENT: A BRIEF APPROACH}

\begin{abstract}
The generator of residue from civil construction are responsable for observing the patterns provided on the specified legislation, regarding the final dispose, making its internal and external management. The ambiental compromise and the economical feasibility must guarantee the sustainability, the conditions and solutions for the final destination of residues, it's municipal management competency to adapt the places to receive such residue. The objective of this article is create new discussions around the subject

\footnotetext{
${ }^{1}$ Este trabalho faz parte das discussões realizadas durante a disciplina Políticas Públicas Ambientais e Gerenciamento de Resíduos oferecida no Mestrado em Meio Ambiente e Desenvolvimento Regional MMADRE da UNOESTE de Presidente Prudente - SP

${ }^{2}$ Engenheiro Civil, aluno especial na disciplina Políticas Públicas Ambientais e Gerenciamento de Resíduos Sólidos, do curso de Mestrado em Meio Ambiente e Desenvolvimento Regional - UNOESTE. arialencar2009@hotmail.com

${ }^{3}$ Docente da disciplina Políticas Públicas Ambientais e Gerenciamento de Resíduos Sólidos do curso de Mestrado em Meio Ambiente e Desenvolvimento Regional - UNOESTE. edilene@unoeste.br
} 
from a brief approach about the Plan of Residue Management from Civil Construction, and for this goal, the methodology used was the collect of data obtained by bibliographic research.

Key-words: Residue of civil construction. Residue management. Environment.

\section{PLAN DE GESTIÓN DE RESIDUOS DE LA CONSTRUCCIÓN: UNA BREVE APROXIMACIÓN}

\section{RESUMEN}

Los generadores de residuos de la construcción son responsables del cumplimiento de las normas especificadas en el específico, relacionado con las leyes de eliminación, por lo que su gestión interna y externa. El compromiso ambiental y viabilidad económica deberían garantizar la sostenibilidad, la condición y la solución para la eliminación de residuos, y la competencia de la medida la administración municipal los sitios para recibir este tipo de residuos. El propósito de este artículo es animar a continuar el debate sobre el tema desde una breve aproximación al Plan de Gestión de Residuos de la Construcción, y para este propósito, la metodología utilizada fue los datos de la encuesta obtenidos por medio de la literatura.

Palabras clave: residuos de la construcción. Gestión de residuos. Medio Ambiente.

\section{INTRODUÇÃO}

A geração dos resíduos da construção civil (RCC) nas cidades cresceu acentuadamente nos últimos anos em virtude de vários fatores como o crescimento econômico, a melhoria da renda da população e pela concentração demográfica nas áreas urbanas.

Segundo Takenaka, Arana e Albano (2012,p.179):

A concentração populacional nas áreas urbanas trouxe alguns desequilíbrios na medida em que houve a ampliação da demanda por moradias, alimentação, escolas, hospitais, saneamento básico entre outros, exigindo um planejamento urbano nem sempre presente nos centros urbanos.

Assim, o processo de urbanização caracterizado pelo deslocamento de moradores da área rural para áreas urbanas associadas ao desenvolvimento da civilização e da tecnologia. Tal fenômeno culmina com a redistribuição das populações das zonas rurais para as cidades em busca de melhores condições de 
vida trazendo a necessidade de ampliação no número de moradias nos centros urbanos.

De acordo com Deák \& Schiffer (1999) e Ojima (2007), quando nos referimos ao processo de crescimento urbano, dois fatores devem ser considerados: o populacional e o padrão de expansão física das ocupações urbanas.

Leite e Award (2012, p.14), comentam a gravidade da questão que envolve o crescimento desordenado das cidades e dos resíduos nela gerados ao afirmar que:

\begin{abstract}
A cidade é a pauta: o século 19 foi dos impérios, o século 20, das nações, o século 21 é das cidades. As megacidades são o futuro do Planeta Urbano. Devem ser vistas como oportunidades e não problema.

O desenvolvimento sustentável se apresenta mais urgentemente onde mora o problema: as cidades darão as respostas para o futuro verde. Nelas se consomem os maiores recursos do planeta; nelas se geram os maiores resíduos.
\end{abstract}

O aumento populacional e a sua concentração nos centros urbanos apresentam números expressivos no que se refere à ampliação dos RCC gerados a partir das atividades da construção civil.

Estes RCC, usualmente chamados de entulhos, são considerados como material inerte, provenientes das ações de construções de novas edificações, ampliações e reformas das edificações já existentes, e também da demolição para propiciar novas edificações a serem construídas no mesmo local.

Pinto e González (2005) afirmam que a origem dos resíduos da construção e demolição, na maioria das cidades, $20 \%$ advém das residências novas, $21 \%$ das edificações novas (acima de $300 \mathrm{~m}^{2}$ ) e 59\% de reformas, ampliações e demolições. Desse total, afirmam ainda os citados autores que a construção civil apresenta-se como uma atividade produtiva geradora de grandes quantidades de resíduos sólidos devido, principalmente, ao desperdício de materiais ocorrido nos próprios canteiros de obras $^{4}$

\footnotetext{
${ }^{4}$ Segundo estudo realizado pela UFMG intitulado Alternativas para a Redução do Desperdício de Materiais nos Canteiros de Obras, uma das maiores causas do desperdício nas construções está no próprio layout dos canteiros e à mão-de-obra desqualificada. Disponível em: http://perdas.pcc.usp.br/. Acesso em 24/10/2012.
} 
Em virtude desse desperdício de RCC e do acúmulo dos mesmos, provenientes das reformas e demolições, acabam aumentando o custo final da obra. Estes resíduos nem sempre são dispostos em locais adequados, sendo que devem ser gerenciados de maneira correta para que não venham a contribuir para a degradação do meio ambiente bem como, causar danos à saúde da população.

Takenaka, Arana e Albano (2012,p.181) reforçam tal afirmação ao concluir que:

\begin{abstract}
Podemos deduzir que em todas as fases de um empreendimento ocorrem perdas de materiais que, somadas às perdas (materiais sólidos que sobram em suas diversas fases e que, uma vez incorporados e não utilizados somam-se à quantidade de entulho gerado) dos demais empreendimentos no município necessitam de um adequado gerenciamento e disposição final.
\end{abstract}

Dessa forma, falar da questão ambiental no que tange à disposição final dos RCC exige um entendimento acerca dos problemas que envolvem o tema com enfoque direto sobre os impactos negativos ao meio ambiente causados por sua inadequada disposição final.

Tais impactos negativos podem ser apontados como a degradação das áreas de manancial e de proteção permanente, a proliferação de agentes transmissores de doenças, o assoreamento de rios e córregos, a obstrução dos sistemas de drenagem (galerias, sarjetas, etc), a ocupação de vias e logradouros públicos por resíduos (com prejuízo à circulação de pessoas e veículos), além da degradação da paisagem urbana. (BARROS, 2012)

Assim, a implantação de um Plano de Gerenciamento de Resíduos da Construção Civil pode trazer, efetivamente, medidas de destinação e disposição final corretas dos RCC, bem como estratégias e medidas para a minimização dos impactos socioambientais gerados pelos mesmos.

\title{
1.1 RCC e a municipalidade
}

O presente artigo, como já observado, não pretende esgotar o assunto acerca da necessidade da implantação de um Plano de Gerenciamento de Resíduos da 
Construção Civil e sim, propiciar condições de debate a partir de uma breve abordagem sobre o tema.

O Estatuto das Cidades, Lei Federal n.. 10.257, promulgada em 16/06/2001, determinou novas diretrizes para o desenvolvimento sustentável das cidades brasileiras, previu a necessidade de proteção e preservação ao meio ambiente natural e construído, e exigiu dos municípios que adotassem políticas de gestão quanto aos resíduos sólidos gerados a partir de decisões articuladas com o Plano Diretor de cada município ${ }^{5}$.

Em tal contexto aprovou-se a Resolução $n . .9307$, em 05/07/2002, pelo Conselho Nacional do Meio Ambiente - CONAMA, que estabeleceu diretrizes, critérios e procedimentos para a gestão dos resíduos da construção civil, além de classificar os resíduos da construção civil nas classes A, B, C e D. Implica que seus geradores devem priorizar a "não geração" de resíduos, a redução de geração, a reutilização, a reciclagem e a destinação final adequada, seguindo uma lógica préestabelecida. Salientando a necessidade de que os municípios criem Planos de Gerenciamento de Resíduos da Construção Civil, e indique a sua destinação final para cada tipo de resíduo de acordo com a sua classificação.

A Resolução n.. 307, de 05/07/2001, criou instrumentos para que os municípios exercessem a responsabilidade e o dever quanto a implantação de um Plano de Gerenciamento dos Resíduos da Construção Civil. Cada município teria um dever no conjunto de ações em relação aos RCC, visando os seguintes objetivos: destinação adequada dos grandes volumes, preservação e controle das opções de aterro, disposição facilitada de pequenos volumes, melhoria da limpeza e da paisagem urbana, preservação ambiental, incentivo às parcerias, incentivo à presença de novos agentes de limpeza e por fim, incentivo à redução de resíduos na fonte e redução dos custos municipais.

O Plano de Gerenciamento dos Resíduos da Construção Civil deve ser composto pelo Programa Municipal de Gerenciamento de Resíduos da Construção Civil, destinado aos pequenos geradores e em áreas de descartes cadastradas (pontos de entrega), e pelo Projeto de Gerenciamento de Resíduos da Construção

${ }^{5}$ O Plano Diretor é obrigatório para os municípios com mais de 20 mil habitantes. 
Civil, destinado aos grandes geradores (construtoras), compromissados com uso de transportes cadastrados e áreas de manejo licenciadas.

Os Projetos de Gerenciamento de Resíduos da Construção Civil devem contemplar as seguintes etapas:

- Caracterização: nessa etapa o gerador deverá identificar e quantificar os resíduos;

- Triagem: deverá ser realizada, preferencialmente, pelo gerador na origem, ou ser realizada nas áreas de destinação licenciadas para essa finalidade, respeitadas as classes de resíduos;

- Acondicionamento: o gerador deverá garantir o confinamento dos resíduos após a geração até a etapa de transporte assegurando em todos os casos em que possível, as condições de reutilização e da reciclagem;

- Transporte: deverá estar de acordo com as normas técnicas vigentes para o transporte de resíduos.

Tais ações necessitam de aportes financeiros que podem ser obtidos junto a agentes financeiros do Governo Federal, Estadual e/ou Municipal, bem como a empresas do setor privado.

O financiamento das ações relacionadas à Modalidade de Resíduos da Construção Civil está sujeito ao atendimento dos requisitos técnicos e legais para a liberação do financiamento. Essas exigências visam a garantia do empreendimento proposto, para que se insira num contexto de sustentabilidade política e financeira.

Por isso, os aspectos institucionais e operacionais da coleta, transporte, transformação e destinação final desses resíduos, propostos para os municípios, precisam estar claramente estabelecidos nesse plano.

As instalações e as operações previstas no empreendimento proposto devem estar em conformidade com as exigências legais de licenciamento ambiental, sendo a licença ambiental ou a sua dispensa, conforme manifestação do órgão competente, condição primordial para a contratação do financiamento. 


\section{CONSIDERAÇÕES FINAIS}

A partir da implantação do Plano de Gerenciamento dos Resíduos da Construção, o município em questão deve propor uma disposição adequada dos RCC, bem como estratégias e medidas para a minimização dos impactos socioambientais gerados pelos mesmos.

Entretanto, salientamos a necessidade de uma conscientização por parte de todos os cidadãos, dado que um plano de tamanha magnitude exige o comprometimento de toda a municipalidade e também de seus munícipes.

Sabemos que o gerenciamento dos RCC não é uma tarefa simples. Incentivar e disseminar a política da reciclagem e da reutilização dos RCC é um meio de garantir o uso adequado dos recursos naturais e a qualidade de vida da população.

Importante apontar ainda, que, a implantação de um Plano de Gerenciamento dos Resíduos da Construção Civil pode trazer, a médio e longo prazo, a redução da necessidade de novas áreas para o aterro, devido à diminuição do volume de resíduos a serem depositados.

\section{REFERÊNCIAS}

BARROS, R. M. Tratado sobre resíduos sólidos: gestão, uso e sustentabilidade. Rio de Janeiro: Interciência; Minas Gerais: Acta, 2012.

DEÁK, C. \& SCHIFFER, S. R. (Orgs.). O processo de Urbanização no Brasil. 1. ed., São Paulo: EDUSP, 1999.

LEITE, C.; AWARD, J.D.C.M. Cidades Sustentáveis, Cidades Inteligentes, Desenvolvimento Sustentável num Planeta Urbano. Porto Alegre: Bookman, 2012.

OJIMA, R. Dimensões da urbanização dispersa e proposta metodológica para estudos comparativos: uma abordagem socioespacial em aglomerações urbanas brasileiras. Rev. bras. estud. popul., São Paulo, v. 24, n. 2, Dec. 2007

PINTO, T. P.; GONZÁLEZ, J. L. R. Manejo e Gestão de resíduos Da Construção Civil. Brasília: CAIXA, 2005.

PINTO, T. P. Gestão Ambiental de Resíduos da Construção Civil: a experiência do SindusCon-SP. São Paulo: Obra Limpa: I\&T: SindusCon-SP, 2005.

TAKENAKA, E. M. M.; ARANA A. R. A.; ALBANO, M. P. Construção civil e resíduos sólidos: coleta e disposição final no município de Presidente Prudente-SP. Periódico Eletrônico. VIII Fórum Ambiental da Alta Paulista, v. 8, n. 12, 2012, p. 177-186. Disponível em: 
Volume 10, Número 4, 2014

Dilemas da

Sustentabilidade Urbana

http://amigosdanatureza.org.br/publicacoes/index.php/forum_ambiental/article/view/363. Acesso em 12/jul/2014. 